\title{
Human Diversity of Killer Cell Immunoglobulin-Like Receptors and Human Leukocyte Antigen Class I Alleles and Ebola Virus Disease Outcomes
}

\begin{abstract}
Tony Wawina-Bokalanga, Bert Vanmechelen, Valentine Lhermitte, Joan Martí-Carreras, Valentijn Vergote, Fara Raymond Koundouno, Joseph Akoi-Boré, Ruth Thom, Tom Tipton, Kimberley Steeds, Kéita Balla Moussa, Ablam Amento, Lies Laenen, Sophie Duraffour, Martin Gabriel, Paula Ruibal, Yper Hall, Mandy Kader-Kondé, Stephan Günther, Guy Baele, Cesar Muñoz-Fontela, Johan Van Weyenbergh, Miles W. Carroll, Piet Maes
\end{abstract}

We investigated the genetic profiles of killer cell immunoglobulin-like receptors (KIRs) in Ebola virus-infected patients. We studied the relationship between KIR-human leukocyte antigen (HLA) combinations and the clinical outcomes of patients with Ebola virus disease (EVD). We genotyped KIRs and HLA class I alleles using DNA from uninfected controls, EVD survivors, and persons who died of EVD. The activating 2DS4-003 and inhibitory 2DL5 genes were significantly more common among persons who died of EVD; 2DL2 was more common among survivors. We used logistic regression analysis and Bayesian modeling to identify 2DL2, 2DL5, 2DS4-003, HLA-B-Bw4-Thr, and HLA-B-Bw4-lle as probably having a significant relationship with disease outcome. Our findings highlight the importance of innate immune response against Ebola virus and show the association between KIRs and the clinical outcome of EVD.

Author affiliations: KU Leuven, Leuven, Belgium

(T. Wawina-Bokalanga, B. Vanmechelen, V. Lhermitte,

J. Martí-Carreras, V. Vergote, L. Laenen, G. Baele,

J. Van Weyenbergh, P. Maes); University Julius Nyerere of Kankan, Conakry, Guinea (F.R. Koudouno); Institut National de Santé Publique, Conakry (J. Akoi-Boré); Public Health England,

Salisbury, UK (R. Thom, T. Tipton, K. Steeds, Y. Hall,

M.W. Carroll); Centre d'Excellence de Formation et Recherche sur les Maladies Prioritaires en Guinée, Conakry (K.B. Moussa,

A. Amento, M. Kader-Kondé); German Center for Infection

Research, Hamburg-Lübeck-Borstel-Riems, Germany

(S. Duraffour, M. Gabriel); Bernhard Nocht Institute for Tropical Medicine, Hamburg, Germany (S. Duraffour, M. Gabriel, P. Ruibal,

S. Günther, C. Muñoz-Fontela)

DOI: https://doi.org/10.3201/eid2701.202177
Dola virus (EBOV) is an enveloped, nonsegment工ed, negative-sense, single-stranded RNA virus that belongs to the genus Ebolavirus in the family Filoviridae. This genus comprises 6 species recognized by the International Committee on Taxonomy of Viruses: Zaire ebolavirus, Sudan ebolavirus, Bundibugyo ebolavirus, Tai Forest ebolavirus, Reston ebolavirus, and the recently discovered Bombali ebolavirus (1).

Since the first recorded Ebola virus outbreaks in 1976 in Zaire (now the Democratic Republic of the Congo [DRC]) and southern Sudan, other outbreaks of Ebola virus disease (EVD) have been reported in Africa. The West Africa Ebola virus outbreak in 20132016, which mainly affected Guinea, Liberia, and Sierra Leone, was the largest and most widespread EVD outbreak. According to the World Health Organization, this outbreak comprised 28,646 confirmed, probable, and suspected EVD cases and caused 11,323 reported deaths (2).

On June 25, 2020, the DRC's Ministry of Health declared the second largest EVD outbreak to be over (3). According to the DRC's Ministry of Health, this outbreak caused 3,470 confirmed and probable EVD cases. A total of 2,299 infected persons died, and 1,171 persons survived.

EBOV quickly overwhelms the host's innate immune response and causes an acute febrile illness along with headache, vomiting, abdominal pain, diarrhea, severe fatigue, coagulation disorders, hypotension, lymphopenia, and thrombocytopenia $(4,5)$. Some EBOV infections generate a cytokine storm, which hinders peripheral natural killer 
cells (NK) and T and B lymphocytes. This response can induce multiorgan failure, hypovolemic shock, and death (6).

NK cells, among other cells, are key effector cells of the innate immune system and play a crucial role in the antiviral response. The effector capability of NK cells has been described in a wide range of viral infections, such as hepatitis $B$, hepatitis C (HCV), HIV, and human cytomegalovirus infection (7). Few studies have examined NK cell levels and function in EVD patients; those studies documented lower NK cell levels among persons who died of EVD compared with survivors $(8-10)$. One study also observed an increase in inhibitory receptor KIR2DL1 in NK cells during EVD (8). In addition, researchers have demonstrated the cytotoxic effect of NK cells during experimentally induced EBOV infection in nonhuman primates and its protective and deleterious effects in NKdepleted mice (11-14). Activated NK cells respond to EBOV-infected cells by releasing perforin and granzyme, which mediate the cytolysis of EBOVinfected cells. Furthermore, the ability of NK cells to secrete cytokines such as interferon- $\gamma$, interferon$\alpha / \beta$, and tumor necrosis factor- $\alpha$ is essential to the immune response (5). Reed et al. demonstrated that lethal EBOV infection is associated with loss and decreased activity of NK cells (11). In addition, Cimini et al. observed that patients who died of EVD had lower NK cell frequencies than patients who survived (8). The mechanism behind this association is still unknown; however, the degree of loss is highly correlated with fatal disease outcome.

The cytotoxic and secretory functions of NK cells are regulated through the interaction between human leukocyte antigens (HLA) class I molecules on target cells and receptors, such as the killer cell immunoglobulin-like receptors (KIRs), on NK cells (15). KIRs are members of the immunoglobulin superfamily type I receptors, and they are encoded by a family of highly polymorphic genes located on human chromosome 19q13.4 within the leukocyte receptor complex (16). They are expressed on the surface of NK cells and certain T lymphocytes and regulate the function and development of these cells. NK cells recognize HLA class I molecules on the surface of host cells, enabling them to distinguish between self and nonself and to target infected or malignant cells for lysis (17).

Researchers have identified 16 KIR genes, of which 8 are inhibitory (2DL1-5,3DL1-3), 6 are activating $(2 D S 1-5,3 D S 1)$, and 2 are pseudogenes (2DP1 and 3DP1). Some KIRs, such as 2DL4, 3DL2, and
3DL3, contain sequences for activating and inhibitory receptors (18). Inhibitory KIRs interact with specific motifs of HLA class I molecules. One such motif is the amino acid at position 80 of HLA: lysine or asparagine for HLA-C alleles and threonine or isoleucine for HLA-B-Bw4 and HLA-A-Bw4 alleles (19).

The number and types of KIRs vary considerably among individual persons, who might exhibit 7-12 KIRs for each haplotype. A person might have haplotype $A$, which exhibits more inhibitory KIRs, or haplotype $B$, which exhibits more activating KIRs (19). The $\mathrm{AB}$ or $\mathrm{BB}$ haplotype is characterized by the presence of the 2DL2, 2DL5, 3DS1, 2DS1, 2DS2, $2 D S 3$, or 2DS5 genes. None of these genes are present in the AA haplotype, which contains only a single activating KIR gene, 2DS4 (with a deleted variant of $22 \mathrm{bp}$ in exon 5, 2DS4-003) (20). Because these genes are so variable and the KIR/HLA combinations play a key role in immune response, understanding this variability is important for genotyping studies (21). Genetic studies have shown that the distribution of KIR genes and KIR/HLA combinations vary widely; furthermore, these variations can predict disease outcomes in persons with hepatitis $\mathrm{B}, \mathrm{HCV}$, human T-lymphotropic virus type 1 (HTLV-1), or HIV-1 infections $(22,23)$. During HIV-1, HCV, or HTLV-1 infection, CD8+ cells mediate much of the protective effect of inhibitory KIRs (24).

We determined the genetic profiles of KIR genes and HLA class I alleles in DNA samples from persons infected with EBOV Makona variant in Guinea. We also assessed the distribution of HLA class I genotypes during an EVD outbreak and the relationship between specific KIR/HLA combinations and the clinical outcomes of persons with EVD.

\section{Materials and Methods}

\section{Study Samples}

We studied samples from patients in whom EVD was diagnosed during the 2013-2016 outbreak. We collected serum samples from 77 uninfected controls and 101 EVD survivors in Guéckédou, Guinea, during May 2015-September 2017. In addition, the European Mobile Laboratory provided DNA isolated from whole blood samples of 119 persons who had died of EVD.

We defined EVD survivors as EBOV-infected patients who had survived the acute phase of EVD and were discharged from the Ebola treatment center in Guéckédou after testing negative for Ebola 4 times by reverse transcription PCR. The survivors in our study included only persons with an original certificate of 
survivorship issued by the Guinean government. Controls tested negative for EBOV-specific antibodies and EBOV neutralizing antibodies in plasma.

We collected blood samples in EDTA tubes for routine blood tests, serologic assays for EBOV antigen, and nucleic acid detection of EBOV RNA by reverse transcription PCR. Afterward, we isolated peripheral blood mononuclear cells (PBMCs) from whole blood samples using Ficoll-Paque density gradient centrifugation (Sigma-Aldrich Inc., https:// www.sigmaaldrich.com) according to the manufacturer's instructions. To store PBMCs at room temperature, we used DNAgard Blood (Sigma-Aldrich Inc.) according to the manufacturer's instructions.

\section{Genomic DNA Extraction}

We extracted genomic DNA from PBMCs from EVD survivors and controls. We used the QIAamp DNA Mini kit (QIAGEN, https://www.qiagen.com) for DNA extraction according to the manufacturer's instructions. We eluted the purified DNA in $100 \mu \mathrm{L}$ buffer AE and quantified it using a NanoDrop spectrophotometer (ThermoFisher Scientific, https:/ / www. thermofisher.com).

\section{Whole-Genome Amplification}

We conducted whole-genome amplification of DNA samples using the multiple displacement amplification Repli-g mini kit (QIAGEN) according to the manufacturer's instructions. We then purified DNA with a rapid in-house method using ethanol precipitation. For this procedure, we first mixed 1:10 volume sodium acetate ( $3 \mathrm{M}, \mathrm{pH} 5.5$ ) with 2 volumes absolute ethanol in a $1.5 \mathrm{~mL}$ Eppendorf tube. After inverting the tube, we incubated the reaction mixture at $-80^{\circ} \mathrm{C}$ for $2 \mathrm{~h}$ and then centrifuged at 20,000 $\times \mathrm{g}$ for $30 \mathrm{~min}$. We withdrew the supernatant and washed the pellet with $70 \%$ ethanol, then centrifuged the mixture at maximum speed for $15 \mathrm{~min}$. After removing the supernatant, we air-dried the pellet at $50^{\circ} \mathrm{C}$ and then resuspended in $50 \mu \mathrm{L}$ buffer $\mathrm{AE}$. We stored the extracted DNA products at $-20^{\circ} \mathrm{C}$.

\section{KIR and HLA Class I Genotyping}

We established the presence or absence of $14 \mathrm{KIR}$ genes and 2 pseudogenes (2DP1 and 3DP1) by PCR using primers, as published in previous studies (2527). We used Primer3 version 0.4 .0 software (https:/ / bioinfo.ut.ee/primer3-0.4.0) to design specific primers targeting 2DL5 and 2DS4-001. We conducted HLA genotyping for 5 HLA class I alleles known to be KIR ligands: HLA-C1-Asn80 (2DL2, 2DL3, and 2DS2), HLA-C2-Lys80 (2DL1 and 2DS1), HLA-B-Bw4-
Thr80 (3DL1), HLA-B-Bw4-Ile80 (3DS1 and 3DL1), and HLA-A-Bw4 (3DL1 and 3DL2) (28) (Appendix Table 1, https://wwwnc.cdc.gov/EID/article/27/1/202177-App1.pdf).

We conducted PCR on amplified genomic DNA from uninfected controls, EVD survivors, and persons who died of EVD. We conducted amplifications using a Biometra TRIO-Analytik Jena Thermocycler (Westburg, https://www.westburg.eu). For each PCR, we used a $30 \mu \mathrm{L}$ mixture containing $\geq 10 \mathrm{ng}$ of DNA sample, $6 \mu \mathrm{L} 5 \times$ QIAGEN OneStep reverse transcription PCR buffer, $1 \mu \mathrm{L}$ dNTP mix with $10 \mathrm{mM}$ of each dNTP, $1 \mu \mathrm{L}$ QIAGEN OneStep reverse transcription PCR enzyme mix, $0.6 \mu \mathrm{M}$ of each primer, and RNasefree water. In negative samples, we also added 0.6 $\mu \mathrm{M}$ of an internal control primer set to verify the true absence of KIR genes and HLA class I alleles. We ran each PCR in triplicate (Appendix Tables 2,3). We ran the amplified DNA on $6 \%$ polyacrylamide gels and electrophoresed it in 1× Tris-borate-EDTA buffer. We stained gels with Midori green direct and visualized them under UV light using a gel imager camera.

\section{Statistical Data Analysis}

We tested the difference in frequency of KIR/HLA haplotypes using the Fisher exact test. To avoid type I error, we calculated an adjusted $p$ value with Bonferroni correction and used the resulting $p$ value $(p<0.02)$ to determine significance. We conducted binary logistic regression to assess the effect of HLA and KIR genotypes on the clinical outcome of patients with EVD. We selected any variable with a significant univariate test at a relaxed $p$ value of 0.25 as a candidate for the multivariate analysis. This criterion enabled us to reduce the initial number of variables (i.e., genes) in the model, while simultaneously reducing the risk of missing important variables $(29,30)$. After preselection, we built a binomial logistic regression model that comprised all remaining explanatory variables and performed backward elimination. The model simultaneously used Bayesian information criterion (31) and Fisher exact tests at the $5 \%$ significance level.

As an extension to the binomial analysis, we conducted multinomial logistic regression. This model assessed the effect of HLA and KIR genotypes on the clinical outcome of patients with EVD and determined the KIR gene profile associated with these outcomes. We conducted Bayesian model averaging (BMA) using the R packages BMA and mlogitBMA $(32,33)$. These packages enabled us to account for uncertainty about the explanatory variables using a Bayesian information criterion approximation to the 
posterior model probabilities. After removing variables that generated collinearity issues, we searched the model space using the fast leaps and bounds algorithm (34). As the first step in applying BMA to solve the variable selection problem for multinomial logit data, mlogitBMA uses the approach of Begg and Gray (35), which approximates large-scale multinomial logistic regressions as a series of binary logistic regressions (36).

\section{Ethics Approval}

The National Committee of Ethics in Medical Research of Guinea approved the use of diagnostic leftover samples and corresponding patient data for this study (approval no. 11/CNERS/14). Samples from EVD survivors and controls were collected under ethics protocols approved by the Guinean National Ethics Committee for Research and Health (approval no. 33/CNERS/15). We obtained written and informed consent from controls and EVD survivors. Ethical permission for the work conducted at KU Leuven on the DNA samples was reviewed and approved by the KU Leuven ethics committee under reference no. S58836.

\section{Results}

\section{KIR Haplotypes Associated with EVD Outcome}

Of 77 controls, 101 survivors, and 119 persons who died of EVD, an average of $78 \%$ of each category had 11 shared haplotypes, which differed from each other by the presence or absence of 9 KIR genes (Figure 1). The remaining participants (20 controls, 14 survivors, and 31 persons who died of EVD) had a rare KIR haplotype that lacked $\geq 3 \mathrm{KIR}$ genes (data not shown). The frequency of the KIR AA haplotype was significantly higher for persons who died of EVD $(6.7 \%)$ than for survivors $(0.99 \% ; p=0.04)$. One KIR BB haplotype was significantly more common among the survivors (37.6\%) than among persons who died of EVD (17.6\%; $\mathrm{p}<0.01)$. All participants had the 2DL1, 3DL1, 3DL2, 3DL3, 2DP1, and 3DP1-004 genes.

\section{Frequency of KIR Genotypes}

We found the 2DL2 gene in $98 \%$ of survivors and $83.2 \%$ of persons who died of EVD. Likewise, we found the 2 DL5 gene in $46.5 \%$ of survivors and $63 \%$ of persons who died of EVD (Table 1). These results

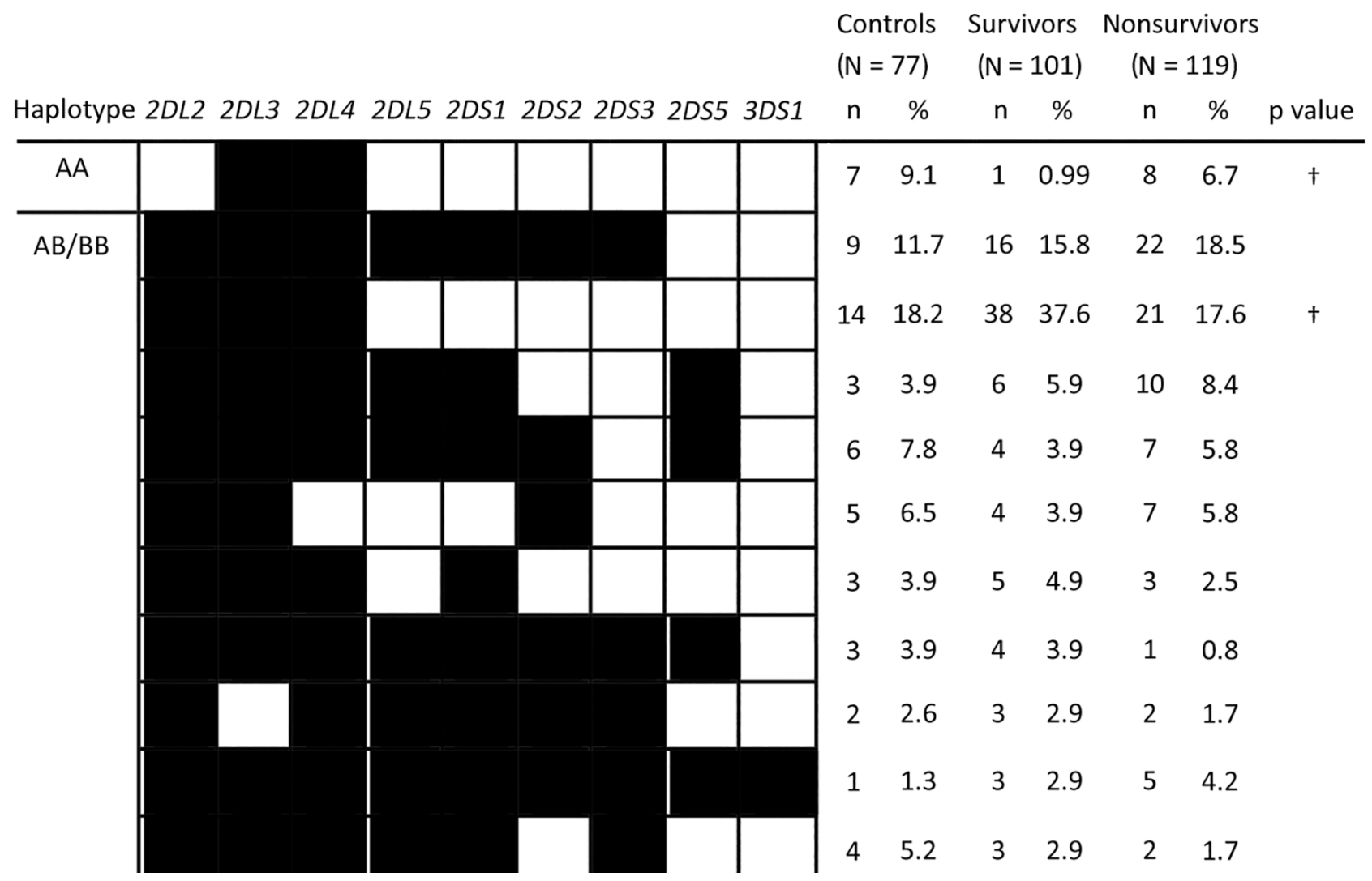

Figure 1. Killer cell immunoglobulin-like receptor haplotypes among the control group, Ebola survivors, and persons who died of Ebola virus disease in Guinea, 2015-2017. Percentage of each haplotype was calculated and defined as the number of persons with the killer cell immunoglobulin-like receptor haplotype $(\mathrm{n})$ divided by the number of persons $(\mathrm{N})$ in the studied group. Black boxes indicate presence of genes; white boxes indicate absence of genes. $\uparrow p<P c$ (survivors vs. fatalities). $P c$, corrected $p$ value. 
Table 1. Frequency of KIR genes and HLA class I alleles among control group, Ebola survivors, and persons who died of Ebola virus disease, Guinea, 2015-2017*

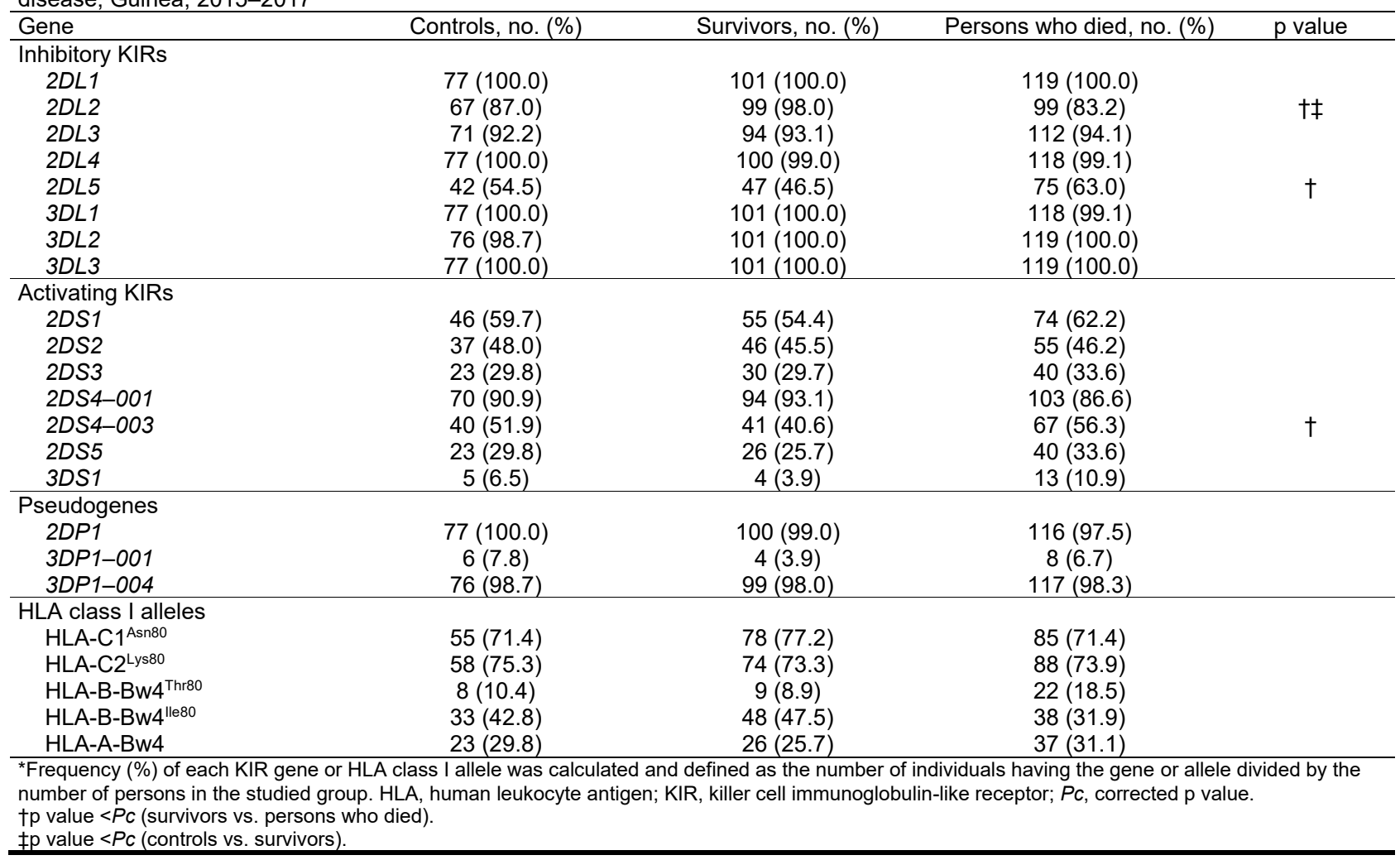

suggest that inhibitory $2 D L 2$ and $2 D L 5$ might be associated with the outcome of persons with EVD.

\section{Relevant KIR Genes and HLA Class I Alleles in Survivors and Persons Who Died of EVD}

The binomial logistic regression model (Table 2) retained 4 KIR genes and 2 HLA class I alleles as covariates in our final model, implying that these genes exhibit a significant relationship with disease outcome. Because of the relatively small number of participants, we validated these findings through BMA. The KIR genes 2DL2, 2DL5, and 2DS4-0003 and the HLA class I alleles HLA-B-Bw4-Thr and HLA-B-Bw4Ile were present in $>15 \%$ of the models explored during our BMA analysis (Table 3; Appendix Figure 1). These 5 covariates are almost identical to those identified in the binary regression models (Tables 2, 3).

\section{HLA Haplotypes}

We identified 23 HLA class I haplotypes. These haplotypes differed by the presence or absence of 2 HLAC, 2 HLA-B, or 1 HLA-A alleles (Figure 2). The HLA haplotype characterized by the presence of HLA$C 1^{A s n 80}$, HLA-C2 ${ }^{L y s 80}$, and HLA-A-Bw4 was significantly more common among persons who died (11.7\%) than survivors $(4.95 \% ; p<0.01)$.

\section{Functional Analysis of HLA and KIR Gene Combinations}

To further evaluate whether biologically relevant KIR/HLA combinations affect the outcome of patients with EVD, we conducted a functional analysis of 5 HLA class I alleles and their respective inhibitory and activating KIRs (Appendix Table 1); we compared the results of uninfected controls, persons who died of EVD, and survivors. We used previously

Table 2. Results from multivariate logistic regression model of human leukocyte antigen class I and killer cell immunoglobulin-like receptor genes in controls and Ebola virus-infected patients, Guinea, 2015-2017

\begin{tabular}{lccc}
\hline Term & $\beta$ estimate & SE & p value \\
\hline Intercept $(\beta 0)$ & -2.27 & 0.84 & $<0.01$ \\
$2 D L 2(\beta 1)$ & 2.73 & 0.82 & $<0.01$ \\
$2 D L 5(\beta 2)$ & -1.94 & 0.67 & $<0.01$ \\
$2 D S 1(\beta 3)$ & 1.35 & 0.67 & $<0.05$ \\
2DS4-0003 $(\beta 4)$ & -0.63 & 0.31 & $<0.05$ \\
HLA-B-Bw4-Thr $(\beta 5)$ & -1.20 & 0.48 & $<0.05$ \\
HLA-B-Bw4-Ile $(\beta 6)$ & 0.76 & 0.31 & $<0.05$ \\
\hline
\end{tabular}


Table 3. Results from the multinomial logistic regression of human leukocyte antigen class I and killer cell immunoglobulin-like receptor genes in Ebola virus-infected patients, Guinea, 2015-2017*

\begin{tabular}{|c|c|c|c|c|}
\hline Term & $p \neq 0$ & $\beta$ estimate & SE & Best model \\
\hline $2 D L 2$ & 88.1 & 1.02 & 0.54 & 1.18 \\
\hline $2 D L 5$ & 59.1 & -0.43 & 0.46 & -0.65 \\
\hline KIR2DS4.0003 & 16.6 & -0.08 & 0.20 & $(\ldots)$ \\
\hline$H L A-B-B w 4-T h r$ & 45.8 & -0.38 & 0.48 & $(\ldots)$ \\
\hline$H L A-B-B w 4-I l e$ & 45.1 & 0.27 & 0.34 & $(\ldots)$ \\
\hline
\end{tabular}

validated functional KIR/HLA pairs (28) to stratify each group of participants into inhibitory and activating KIR/HLA ligands and scored each KIR/HLA combination: 0, absence of both KIR and HLA ligand; 1, presence of either KIR or HLA ligand; 2, weak affinity between KIR and HLA; or 3, strong affinity be- tween KIR and HLA. Survivors had a total inhibitory KIR/HLA score that was significantly higher than in persons who died of EVD ( $\mathrm{p}<0.01$ by Kruskall-Wallis test with false discovery rate correction), whereas no significant difference was observed in the total activating KIR/HLA score Figure 3.

\begin{tabular}{|c|c|c|c|c|c|c|c|c|c|c|c|}
\hline \multirow{2}{*}{$\begin{array}{l}\text { HLA- } \\
\mathrm{Cl}^{\mathrm{Asn} 80}\end{array}$} & \multirow{2}{*}{$\begin{array}{l}\text { HLA- } \\
\mathrm{C}^{\text {Lys } 80}\end{array}$} & \multirow{2}{*}{$\begin{array}{l}\text { HLA alles } \\
\text { HLA-B- } \\
\text { Bw4 }{ }^{\text {Thr80 }}\end{array}$} & \multirow{2}{*}{$\begin{array}{l}\text { HLA-B- } \\
\text { Bw4 } 4^{11280}\end{array}$} & \multirow{2}{*}{$\begin{array}{l}\text { HLA-A- } \\
\text { Bw4 }\end{array}$} & \multicolumn{2}{|c|}{$\begin{array}{l}\text { Controls } \\
(\mathrm{N}=77)\end{array}$} & \multicolumn{2}{|c|}{$\begin{array}{l}\text { Survivors } \\
(N=101)\end{array}$} & \multicolumn{2}{|c|}{$\begin{array}{c}\text { Nonsurvivors } \\
(\mathrm{N}=119)\end{array}$} & \multirow[b]{2}{*}{$p$ value } \\
\hline & & & & & $n$ & $\%$ & $n$ & $\%$ & $n$ & $\%$ & \\
\hline & & & & & 16 & 20.8 & 18 & 17.82 & 20 & 16.8 & \\
\hline & & & & & 3 & 3.9 & 5 & 4.95 & 14 & 11.7 & $\dagger$ \\
\hline & & & & & 5 & 6.5 & 9 & 8.9 & 4 & 3.4 & \\
\hline & & & & & 4 & 5.2 & 11 & 10.9 & 12 & 10.1 & $\ddagger$ \\
\hline & & & & & 10 & 13.0 & 13 & 12.9 & 9 & 7.6 & \\
\hline & & & & & & $\mathrm{np}$ & 1 & 0.99 & 2 & 1.7 & \\
\hline & & & & & 5 & 6.5 & 3 & 2.97 & 5 & 4.2 & \\
\hline & & & & & 6 & 7.8 & 11 & 10.9 & 6 & 5.0 & \\
\hline & & & & & 5 & 6.5 & 2 & 2.0 & 7 & 5.9 & \\
\hline & & & & & & $\mathrm{np}$ & & $\mathrm{np}$ & 5 & 4.2 & \\
\hline & & & & & 7 & 9.0 & 8 & 7.9 & 4 & 3.4 & \\
\hline & & & & & 5 & 6.5 & 7 & 6.9 & 14 & 11.7 & \\
\hline & & & & & 2 & 2.6 & 5 & 4.95 & 4 & 3.4 & \\
\hline & & & & & 1 & 1.3 & 1 & 0.99 & 2 & 1.7 & \\
\hline & & & & & 2 & 2.6 & & $\mathrm{np}$ & 2 & 1.7 & \\
\hline & & & & & 3 & 3.9 & 4 & 3.96 & 2 & 1.7 & \\
\hline & & & & & 1 & 1.3 & & $\mathrm{np}$ & 2 & 1.7 & \\
\hline & & & & & 1 & 1.3 & & $\mathrm{np}$ & 1 & 0.8 & \\
\hline & & & & & 1 & 1.3 & & $\mathrm{np}$ & 1 & 0.8 & \\
\hline & & & & & & $\mathrm{np}$ & 1 & 0.99 & & $\mathrm{np}$ & \\
\hline & & & & & & $\mathrm{np}$ & 1 & 0.99 & & $\mathrm{np}$ & \\
\hline & & & & & & $\mathrm{np}$ & 1 & 0.99 & 2 & 1.7 & \\
\hline & & & & & & $\mathrm{np}$ & & $\mathrm{np}$ & 1 & 0.8 & \\
\hline
\end{tabular}

Figure 2. HLA haplotypes identified among the control group, Ebola survivors, and persons who died of Ebola virus disease in Guinea, 2015-2017. Percentage of each haplotype was calculated and defined as the number of persons with the HLA haplotype (n) divided by the number of individuals $(N)$ in the studied group. Black boxes indicate presence of genes; white boxes indicate absence of genes. $\dagger p<P c$ (survivors vs fatalities); $\ddagger \mathrm{p}<P c$ (controls vs infected cases). HLA, human leukocyte antigen; NP, not present; $P c$, corrected $p$ value. 


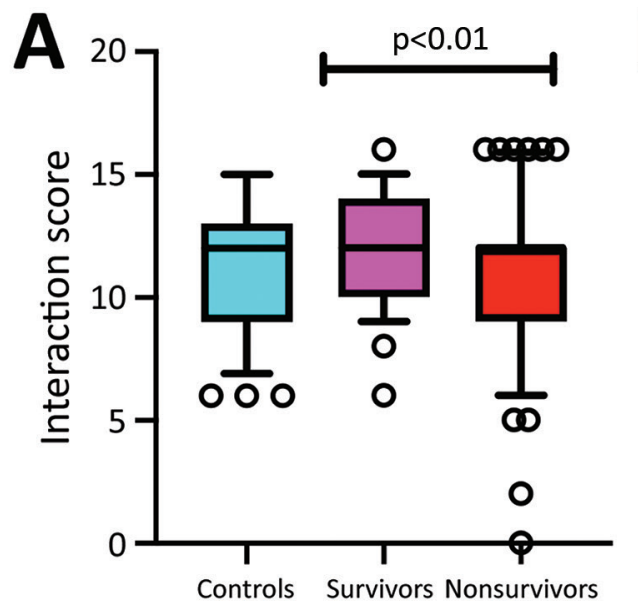

\section{Discussion}

Despite the presumed protective role played by NK cells against EBOV, few studies have been conducted on KIRs and their specific HLA ligands during EVD $(6,37)$. Our study shows that EBOVinfected patients have diverse HLA and KIR genotypes. The KIR haplotype lacking the 2DL2, 2DL5, 2DS1, 2DS2, 2DS3, 2DS5, and 3DS1 genes was significantly more common among persons who died of EVD $(6.7 \%)$ than survivors $(0.99 \%$; $p=0.04)$ (Figure 1). We used BMA analysis to identify the KIR genes 2DL2, 2DL5, and 2DS4-003 as possibly associated with disease outcomes. Contrary to findings by Wauquier et al. (37), we found that frequencies of activating 2DS1 and 2DS3 were not significantly correlated with disease outcomes. In addition, the KIR 2DS4-003 and 2DL5 genes were significantly more common among persons who died of EVD than among survivors. This discrepancy might be caused by differences in sample size or genetic makeup of the study populations.

Using the KIR Allele Frequency Net Database (http://www.allelefrequencies.net), we compared the frequency of inhibitory and activating KIR genes from this study with different populations. These populations were from countries in West Africa (i.e., Côte d'Ivoire, Nigeria, Ghana, Equatorial Guinea, and Senegal), Central Africa (i.e., DRC, Gabon, and Uganda), South Africa (i.e., South Africa and Zimbabwe), and a group of mixed population from Reunion, Comoros, and South Africa. Inhibitory 2DL2 and activating 2DS1 frequencies were higher for our study group than for all other studied populations from West Africa $(p<0.01)$, Central Africa $(p<0.01)$, and South Africa $(p<0.01)$ (Appendix Figure 2). The apparent discrepancy between our study and that of Wauquier et al. (37) might be largely explained by dif-
Figure 3. Statistical comparison of all inhibitory and activating killer cell immunoglobulin receptors (KIRs) between controls, survivors, and persons who died of Ebola virus disease in Guinea, 2015-2017. A) All inhibitory KIRs with their specific HLA ligands are compared between studied groups. Persons who did and did not survive differed significantly. B) Comparison of activating KIRs with their specific HLA ligands between studied groups. HLA, human leukocyte antigen. ferences in population genetics between Guinea and Gabon, where Wauquier et al. recruited participants. These differences might be promulgated by the rapid evolution of human KIR genes, partly in response to viral diversity (38).

Another study found increased levels of inhibitory KIR 2DL1 at the cell surface of NK cells in EVD patients from Guinea (8) during the same outbreak. However, that study's small sample size did not enable the detection of differences between the 8 survivors and 6 persons who died of EVD. Our data suggests that KIR $2 D L 2$ has a protective role in EVD; similarly, this gene is protective against HIV-1 and HCV infection because it enhances the protective effect of HLA-B57 on viral load, slows the reduction in CD4 count, and enables spontaneous clearance of $\mathrm{HCV}$ (23). On the other hand, KIR 2DL2 strongly enhanced the protective effect of HLA-C8 and the detrimental effect of HLA-B54 on disease outcome in HTLV-1 infection (24). It will be important to further investigate whether the proposed protective effect of KIR 2DL2 in EVD might be mediated by the patient's viral load.

All participants in our study had the KIR 3DL3 gene. Existing data show that $3 D L 3$ transcripts are overexpressed in persons who died of EVD compared with survivors in recovery $(p<0.01)$ and in the viremic phase ( $p=0.17$; data not shown) (39). Our findings support the hypothesis that genomic and transcriptomic mechanisms of KIR regulation play a role in EVD outcomes.

Although persons from all groups had the inhibitory 3DL1 gene, the frequency of its low-affinity ligand HLA-B-Bw $4^{\text {Thro0 }}$ was significantly higher among persons who died $(18.5 \%)$ than among survivors $(8.9 \%)$. In contrast, its high-affinity ligand HLA-B-Bw $4^{\text {Ile80 }}$ allele was more common among survivors $(47.5 \%)$ than among persons who died of EVD (31.9\%). 
In conclusion, EVD survivors express less activating and more inhibitory KIRs (Table 2) and more functional inhibitory KIR/HLA pairs (Figure 3) through genomic and transcriptomic (39) mechanisms, than persons who died of EVD. We hypothesize that these genetic differences contribute to the uncontrolled innate immune response observed in EVD (6). This response is mediated mostly by NK cells, although KIRs might also participate (24).

Although researchers have made substantial advances in drug and vaccine development for EVD in the last 5 years, researchers should also investigate the potential effects of blocking KIR receptors on disease outcome. These biomarkers could lead to new therapeutic approaches, preferentially targeting the innate immune system, for future EVD outbreaks. Our study had a reasonable sample size, but further investigations should examine a larger cohort.

\section{Acknowledgments}

We thank the authorities of Conakry, especially the Ministry of Health and Public Hygiene, for supporting the study. We thank the staff members of the Centre d'Excellence de Formation et Recherche sur les Maladies Prioritaires en Guinée in Conakry for their collaboration. We extend our thanks to John L. Mokili for proofreading the manuscript. We thank Thierry Matonda-Ma-Nzuzi for great support on data analysis. Finally, we gratefully acknowledge all members of the Association des Survivants d'Ebola from Guéckédou and Coyah for being involved in this study.

B.V. is supported by a grant for strategic basic research from Fonds Wetenschappelijk Onderzoek/Research Foundation -Flanders (grant no. 1S28617N). J.M.C. was supported by HONOURs Marie-Sklodowska-Curie training network (grant no. 721367). G.B. acknowledges support from the KU Leuven Internal Funds under grant agreement C14/18/094. This work was supported by the Special Research Fund, KU Leuven Bijzonder Onderzoeksfonds (grant no. C14/17/100), the European Union's Horizon 2020 research and innovation program under grant agreement no. 666100 (EVIDENT) and service contract no. IFS/2011/272-372 funded by European Commission Directorate-General for International Cooperation and Development.

\section{About the Author}

Dr. Wawina-Bokalanga is a doctoral student at KU Leuven-Rega Institute for Medical Research. His research interests include emerging and reemerging viral diseases with a focus on genome sequencing, immunogenetics and public health interventions.

\section{References}

1. Goldstein T, Anthony SJ, Gbakima A, Bird BH, Bangura J, Tremeau-Bravard A, et al. The discovery of Bombali virus adds further support for bats as hosts of ebolaviruses. [Erratum in: Nat Microbiol. 2018;3:1486]. Nat Microbiol. 2018;3:1084-9. https:// doi.org/10.1038/s41564-018-0227-2

2. World Health Organization. Ebola situation reports: archive. 2016 Jun [cited 2019 May 14]. http:/ / www.who.int/csr/ disease/ebola/situation-reports/archive

3. World Health Organization. Ebola in the Democratic Republic of the Congo: North Kivu, Ituri 2018-2020. 2020 Jul [cited 2020 Aug 15]. https:/ / www.who.int/emergencies/ diseases/ebola/drc-2019

4. Ansari AA. Clinical features and pathobiology of ebolavirus infection. J Autoimmun. 2014;55:1-9. https://doi.org/10.1016/j.jaut.2014.09.001

5. Falasca L, Agrati C, Petrosillo N, Di Caro A, Capobianchi MR, Ippolito G, et al. Molecular mechanisms of Ebola virus pathogenesis: focus on cell death. Cell Death Differ. 2015;22:1250-9. https://doi.org/10.1038/cdd.2015.67

6. Wauquier N, Becquart P, Padilla C, Baize S, Leroy EM. Human fatal zaire ebola virus infection is associated with an aberrant innate immunity and with massive lymphocyte apoptosis. PLoS Negl Trop Dis. 2010;4:e837. https://doi.org/10.1371/journal.pntd.0000837

7. Boeijen LL, Hou J, de Groen RA, Verbon A, Boonstra A. Persistent replication of HIV, Hepatitis C virus (HCV), and $\mathrm{HBV}$ results in distinct gene expression profiles by human NK cells. J Virol. 2019;93:e00575-18.

8. Cimini E, Viola D, Cabeza-Cabrerizo M, Romanelli A, Tumino N, Sacchi A, et al. Different features of Vס2 T and NK cells in fatal and non-fatal human Ebola infections. PLoS Negl Trop Dis. 2017;11:e0005645. https://doi.org/10.1371/ journal.pntd.0005645

9. McElroy AK, Akondy RS, Mcllwain DR, Chen H, Bjornson-Hooper Z, Mukherjee N, et al. Immunologic timeline of Ebola virus disease and recovery in humans. JCI Insight. 2020;5:e137260. https:// doi.org/10.1172/ jci.insight. 137260

10. Sanchez A, Lukwiya M, Bausch D, Mahanty S, Sanchez AJ, Wagoner KD, et al. Analysis of human peripheral blood samples from fatal and nonfatal cases of Ebola (Sudan) hemorrhagic fever: cellular responses, virus load, and nitric oxide levels. J Virol. 2004;78:10370-7. https:/ / doi.org/ 10.1128/JVI.78.19.10370-10377.2004

11. Reed DS, Hensley LE, Geisbert JB, Jahrling PB, Geisbert TW. Depletion of peripheral blood T lymphocytes and NK cells during the course of Ebola hemorrhagic fever in cynomolgus macaques. Viral Immunol. 2004;17:390-400. https:/ / doi.org/ 10.1089/vim.2004.17.390

12. Geisbert TW, Hensley LE, Larsen T, Young HA, Reed DS, Geisbert JB, et al. Pathogenesis of Ebola hemorrhagic fever in cynomolgus macaques: evidence that dendritic cells are early and sustained targets of infection. Am J Pathol. 2003;163:2347-70. https:/ / doi.org/10.1016/ S0002-9440(10)63591-2

13. Warfield KL, Perkins JG, Swenson DL, Deal EM, Bosio CM, Aman MJ, et al. Role of natural killer cells in innate protection against lethal Ebola virus infection. J Exp Med. 2004;200:169-79. https:// doi.org/10.1084/jem.20032141

14. Fausther-Bovendo H, Qiu X, He S, Bello A, Audet J, Ippolito G, et al. NK cells accumulate in infected tissues and 
contribute to pathogenicity of Ebola virus in mice. J Virol. 2019;93:e01703-18. https:/ / doi.org/10.1128/JVI.01703-18

15. Marcenaro E, Carlomagno S, Pesce S, Della Chiesa M, Parolini S, Moretta A, et al. NK cells and their receptors during viral infections. Immunotherapy. 2011;3:1075-86. https:/ / doi.org/10.2217/imt.11.99

16. Hsu KC, Chida S, Geraghty DE, Dupont B. The killer cell immunoglobulin-like receptor (KIR) genomic region: gene-order, haplotypes and allelic polymorphism. Immunol Rev. 2002;190:40-52. https:// doi.org/10.1034/ j.1600-065X.2002.19004.x

17. Parham P. MHC class I molecules and KIRs in human history, health and survival. Nat Rev Immunol. 2005;5:20114. https:// doi.org/10.1038/nri1570

18. Pegram HJ, Andrews DM, Smyth MJ, Darcy PK, Kershaw MH. Activating and inhibitory receptors of natural killer cells. Immunol Cell Biol. 2011;89:216-24. https://doi.org/10.1038/icb.2010.78

19. Middleton D, Curran M, Maxwell L. Natural killer cells and their receptors. Transpl Immunol. 2002;10:147-64. https:/ / doi.org/10.1016/S0966-3274(02)00062-X

20. González-Galarza FF, Takeshita LY, Santos EJ, Kempson F, Maia MH, da Silva AL, et al. Allele frequency net 2015 update: new features for HLA epitopes, KIR and disease and HLA adverse drug reaction associations. Nucleic Acids Res. 2015;43(D1):D784-8. https://doi.org/10.1093/ nar/gku1166

21. Passweg JR, Huard B, Tiercy JM, Roosnek E. HLA and KIR polymorphisms affect NK-cell anti-tumor activity. Trends Immunol. 2007;28:437-41. https:// doi.org/10.1016/ j.it.2007.07.008

22. Podhorzer A, Dirchwolf M, Machicote A, Belen S, Montal S, $\mathrm{Paz}$ S, et al. The clinical features of patients with chronic hepatitis $C$ virus infections are associated with killer cell immunoglobulin-like receptor genes and their expression on the surface of natural killer cells. Front Immunol. 2018;8:1912. https://doi.org/10.3389/fimmu.2017.01912

23. Martin MP, Naranbhai V, Shea PR, Qi Y, Ramsuran V, Vince N, et al. Killer cell immunoglobulin-like receptor 3DL1 variation modifies HLA-B*57 protection against HIV-1. J Clin Invest. 2018;128:1903-12. https:/ / doi.org/10.1172/JCI98463

24. Boelen L, Debebe B, Silveira M, Salam A, Makinde J, Roberts $\mathrm{CH}$, et al. Inhibitory killer cell immunoglobulin-like receptors strengthen $\mathrm{CD}^{+} \mathrm{T}$ cell-mediated control of HIV-1, HCV, and HTLV-1. Sci Immunol. 2018;3:3. https:/ / doi.org/ 10.1126/sciimmunol.aao2892

25. Gagne K, Brizard G, Gueglio B, Milpied N, Herry P, Bonneville F, et al. Relevance of KIR gene polymorphisms in bone marrow transplantation outcome. Hum Immunol. 2002;63:271-80. https:/ / doi.org/10.1016/S01988859(02)00373-7

26. Vilches C, Castaño J, Gómez-Lozano N, Estefanía E. Facilitation of KIR genotyping by a PCR-SSP method that amplifies short DNA fragments. Tissue Antigens.
2007;70:415-22. https://doi.org/10.1111/j.1399-0039. 2007.00923.x

27. Tajik N, Shahsavar F, Nasiri M, Radjabzadeh MF. Compound KIR-HLA genotype analyses in the Iranian population by a novel PCR-SSP assay. Int J Immunogenet. 2010;37:159-68. https://doi.org/10.1111/j.1744-313X.2010.00906.x

28. Kulkarni S, Martin MP, Carrington M. The yin and yang of HLA and KIR in human disease. Semin Immunol. 2008;20:343-52. https:// doi.org/10.1016/j.smim.2008.06.003

29. Bendel RB, Afifi AA. Comparison of stopping rules in forward stepwise regression. J Am Stat Assoc. 1977;72:46-53.

30. Costanza MC, Afifi AA. Comparison of stopping rules in forward stepwise discriminant-analysis. J Am Stat Assoc. 1979;74:777-85. https:/ / doi.org/10.1080/01621459.1979.1048 1030

31. Schwarz G. Estimating the dimension of a model. Ann Stat. 1978;6:461-4. https://doi.org/10.1214/aos/1176344136

32. Raftery AE, Painter IS, Volinsky CT. BMA: an R package for Bayesian model averaging. 2005 [cited 2018 Sep 11]. https://www.r-project.org/doc/Rnews/Rnews_2005-2.pdf

33. Sevcikova H, Raftery A. mlogitBMA: Bayesian model averaging for multinomial logit model. 2013. [cited 2018 Sep 22] http://cran.r-project.org/web/packages/mlogitBMA/ index.html

34. Raftery AE. Bayesian model selection in social research. Sociol Methodol. 1995;25:111-63. https:// doi.org/10.2307/ 271063

35. Begg CB, Gray R. Calculation of polychotomous logistic regression parameters using individualized regressions. Biometrika. 1984;71:11-8. https:/ / doi.org/10.2307/2336391

36. Yeung KY, Bumgarner RE, Raftery AE. Bayesian model averaging: development of an improved multi-class, gene selection and classification tool for microarray data. Bioinformatics. 2005;21:2394-402. https:/ / doi.org/10.1093/ bioinformatics/bti319

37. Wauquier N, Padilla C, Becquart P, Leroy E, Vieillard V. Association of KIR2DS1 and KIR2DS3 with fatal outcome in Ebola virus infection. Immunogenetics. 2010;62:767-71. https://doi.org/10.1007/s00251-010-0480-x

38. Augusto DG, Norman PJ, Dandekar R, Hollenbach JA. Fluctuating and geographically specific selection characterize rapid evolution of the human KIR region. Front Immunol. 2019;10:989. https:// doi.org/10.3389/fimmu.2019.00989

39. Reynard S, Journeaux A, Gloaguen E, Schaeffer J, Varet H, Pietrosemoli N, et al. Immune parameters and outcomes during Ebola virus disease. JCI Insight. 2019;4:e125106. https://doi.org/10.1172/jci.insight.125106

Address for correspondence: Piet Maes, Department of Microbiology, Immunology and Transplantation, Division of Clinical and Epidemiological Virology, KU Leuven - Rega Institute for Medical Research, Herestraat 49, BE-3000 Leuven, Belgium; email: piet.maes@kuleuven.be 